\title{
Supraklaviküler brakial pleksus sinir bloğu sonrası gelişen ipsilateral frenik sinir hasarı
}

\author{
Ipsilateral frenic nerve damage after supraclavicular brachial plexus nerve block
}

Yahya Fatih Koçak, Murat Alparslan, Gülçin Aydın

Gönderilme tarihi:31.01.2022

Kabul tarihi:28.02.2022

Öz

Supraklaviküler brakial pleksus sinir bloğu (SBPB) hem anestezi hem de analjezi amacıyla anestezi pratiğinde kullanılmaktadır. Operasyon süresince hastanın bilincinin açık olması, solunum fonksiyonlarında değişimin olmaması, havayolu reflekslerinin korunması ve postoperatif analjezi özelliği ile genel anesteziye kıyasla daha üstündür. Bununla beraber komplikasyonları da mevcuttur. Son yıllarda ultrasonografi (Usg) eşliğinde komplikasyon oranı oldukça azalmıştır. Bu olgumuzda SBPB sonrası gelişen ipsilateral frenik sinir hasarını tartışacağız.

Anahtar kelimeler: Supraklavikular blok, ultrasonografi, frenik sinir hasarı.

Koçak YF, Alparslan M, Aydın G. Supraklaviküler brakial pleksus sinir bloğu sonrası gelişen ipsilateral frenik sinir hasarı. Pam Tıp Derg 2022;15:395-398.

\begin{abstract}
Supraclavicular brachial plexus nerve block (SBPB) is used in anesthesia practice for both anesthesia and analgesia. Sbpb is more preferable due to its advantages over general anesthesia. Some of these advantages are: the patient is conscious, respiratory functions are protected, airway reflexes are preserved and it has postoperative analgesia. However, there are also complications. In recent years, the complication rate with ultrasonography has decreased considerably. In this case, we will discuss the ipsilateral phrenic nerve injury after SBPB.
\end{abstract}

Key words: Supraclavicular block, ultrasonography, phrenic nerve injury.

Kocak YF, Alparslan M, Aydin G. Ipsilateral frenic nerve damage after supraclavicular brachial plexus nerve block. Pam Med J 2022;15:395-398.

\section{Giriş}

Brakial pleksus blokları (BPB) üst ekstremite cerrahisinde uygun anestezi ve analjezi sağlamasıyla popüler hale gelmiştir [1]. Supraklaviküler fossaya yerleştirilen Usg probu ile subklavyen arter, skalen kaslar, plevra ve 1. kosta yapıları görülerek anterior ve medius skalen kasları arasında subklavyen arter lateralinde brakial pleksus görülerek işlem yapılır. BPB'nin komplikasyonları arasında; diafragmatik paralizi birlikteliğinde frenik sinir bloğu, intravasküler enjeksiyon sonrası gelişen lokal anestezi toksisitesi, pnömotoraks ve hematom yer alır [2].

Biz bu olguda literatür eşliğinde SBPB sonrası gelişen ipsilateral frenik sinir hasarını tartışacağız.

\section{Olgu}

Ortopedi ve Travmatoloji Kliniği tarafından sağ olekranonda kitle operasyonu planlanan 40 yaşında, Amerikan Anestezi Uzmanları Derneği (ASA) 2 risk grubu, vücut kitle indeksi 29, Covid pcr testi (-) olan kadın hastanın preoperatif değerlendirmesinde; retinitis pigmentoza ve hipotiroidisi mevcuttu. Tiroid karsinomu nedenli tiroidektomi ve multipl batın operasyonları vardı. Laboratuar değerleri normal olan hastaya SBPB planlandı. Operasyon sabahı blok odasında standart monitorizasyon eşliğinde $0,003 \mathrm{mg} / \mathrm{kg}$ dormicum (Dilemy, Saba) ile sedasyon sağlandı. Hastanın başı yukarı ve supin pozisyonda iken lineer 10-18 MHz ultrasonografi probu (EsaoteMyLab 30, Geneva, Italy) sagittal düzlemde supraklaviküler fossaya yerleştirildi.

Yahya Fatih Koçak, Arş. Gör. Dr. Kırıkkale Üniversitesi Tıp Fakültesi, Anesteziyoloji ve Reanimasyon Anabilim Dalı, Kırıkkale, Türkı̇ye, e-posta: dryahyafatih26@gmail.com (https://orcid.org/0000-0002-3472-0837) (Soumlu Yazar)

Murat Alparslan, Uzm. Dr. Van Gevaş İlçe Devlet Hastanesi, Anesteziyoloji ve Reanimasyon Kliniği, Van, Türkiye, e-posta: muratalp4@hotmail.com (https://orcid.org/0000-0002-9252-8667)

Gülçin Aydın, Doç. Dr. Kırıkkale Üniversitesi Tıp Fakültesi, Anesteziyoloji ve Reanimasyon Anabilim Dalı, Kırıkkale, Türkiye, e-posta: drgulcinaydin@ yahoo.com (https://orcid.org/0000-0001-9672-7666) 
22 gauge 50 mm'lik iğne (Vygon, Écouen, France) in-plane olarak görüntüde subklavyen arter, 1. kosta ve plevra var iken brakiyal pleksus sahasına ilerletildi. Sinir stimülatörü yardımıyla uygun akım sağlanan alanlara $20 \mathrm{ml} \% 0,5$ bupivakain hidroklorür (Buvasin \%0,5, Vem) ve $5 \mathrm{ml} \% 2$ lidokain HCL (Aritmal, Biosel) lokal anestezikleri kullanıldı.

İşlem sonrası duyusal ve motor muayeneler yapıldı. 5. dakikada sağ elin tenar bölgesinde duyusal ve motor blok tam olarak değerlendirildi ancak hipotenar bölgede duyusal ve motor blok parsiyel olarak gözlendi. 10. dakikada dirsek lateraline kadar duyusal ve motor blok tam olarak değerlendirildi ancak; dirsek ve el medialinde duyusal ve motor bloğun parsiyel olarak devam ettiği izlendi. İşlem sonrası 60. dakikada duyusal ve motor blok tam olarak gözlendi. İşlemden 20 dakika sonra hastada ani dispne gelişti. Fizik muayenede sağ akciğer üst segmentte solunum sesleri azalmış olarak duyuldu. Hastanın satürasyonu oda havasında $\% 99$, nabız:96/dk, tansiyonu 148/82 mmHg olarak ölçüldü. Çekilen posteroanterior (PA) akciğer grafisi normal olarak değerlendirildi (Resim 1).

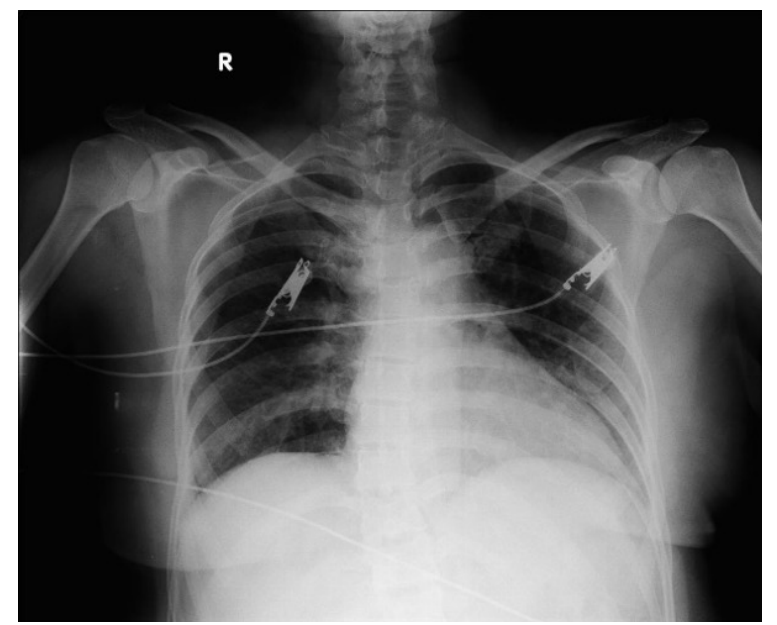

Resim 1. Normal Akciğer grafisi

Dispnenin devam etmesi üzerine operasyon iptal edildi ve hasta yoğun bakım ünitesine alındı. Arteryel kan gazı; $\mathrm{pH}: 7,45 \mathrm{pO}_{2}: 152 \mathrm{mmHg}$ $\mathrm{pCO}_{2}: 30 \mathrm{mmHg} \mathrm{HCo}_{3}: 20 \mathrm{mmol} / \mathrm{Lidi}$. İşlem sonrası 4. Saatte nefes darlığı gerilemeyen hastaya kontrol PA akciğer grafisi- hem inspiryumda hem ekspiryumda çekildi (Resim 2, Resim 3). Toraks bilgisayarlı tomografi (bt) görüntüleme yapıldı (Resim 4). Bu dönemde Oksijen $\mathrm{SpO}_{2} \% 98$, nabız:95/dk, tansiyonu 135/69 mmHg olarak ölçüldü.

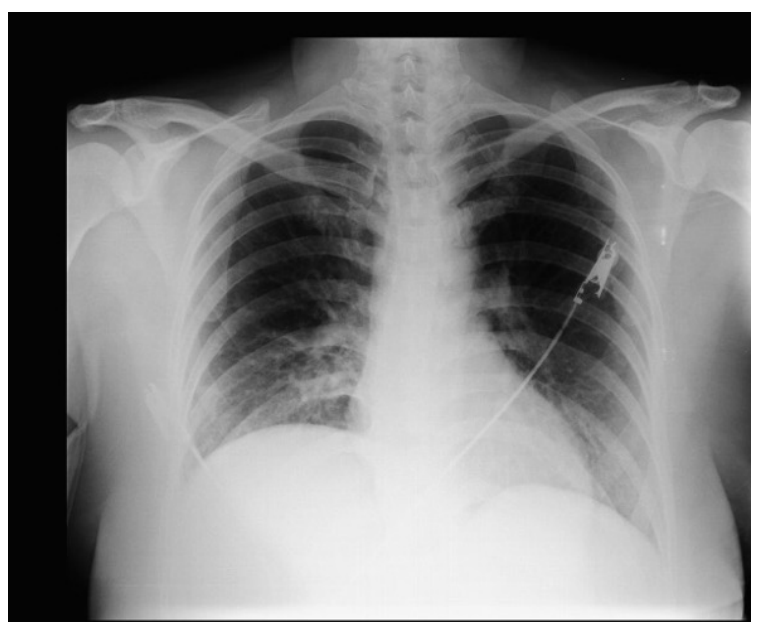

Resim 2. İnspiryumda akciğer grafisinde sağ diafragma eleve

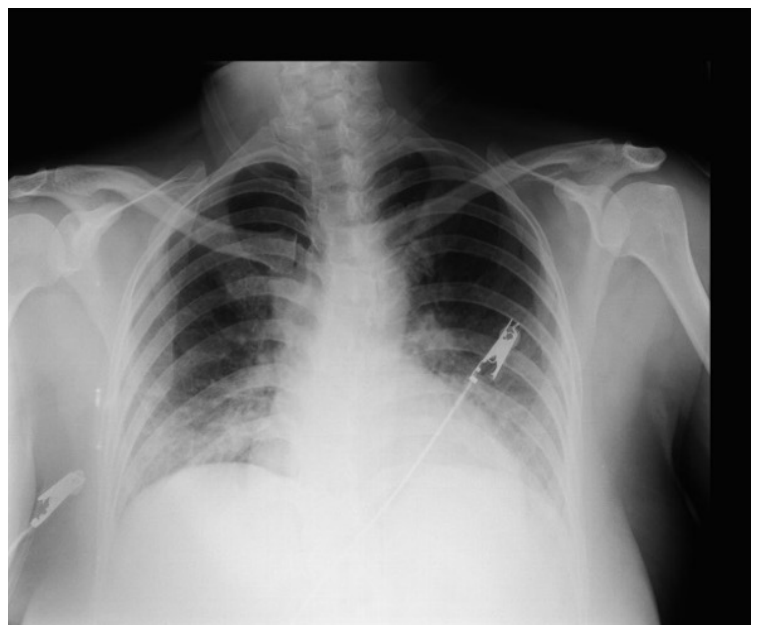

Resim 3. Ekspiryumda akciğer grafisi her iki diafragma aynı seviyede

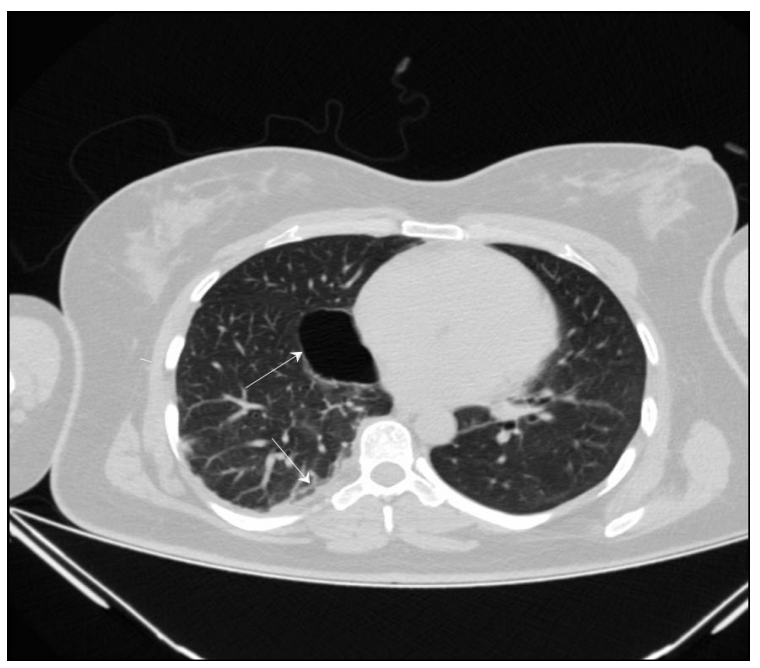

Resim 4. Toraks Bt de üstteki ok ile sağ parakardiyak alanda bül ve alttaki ok ile sağ posterior alanda efüzyon görülmektedir 
Akciğer grafisinde sağ diafragmada inspiryum fazında elevasyon görünürken ekspiryum fazında diafragma aynı seviyede görüldü. Toraks bt'de sağ orta segmentte plevral efüzyon ve parakardiyak bül görüldü. 6 . saatte dispne şikâyeti geriledi. Unilateral frenik sinir paralizisi olarak yorumlanan ve acil girişim düşünülmeyen hasta ertesi gün Ortopedi ve Travmatoloji bölümüne devredildi. Hasta bir gün sonra da taburcu edildi. 4 gün sonra Göğüs Cerrahisi Polikliniği'ne kontrol muayeneye gelen hastanın fizik muayenesi normal her iki hemitoraks solunuma eşit katılıyor olarak değerlendirildi. Çekilen PA akciğer grafisi (Resim 5) ise normaldi.

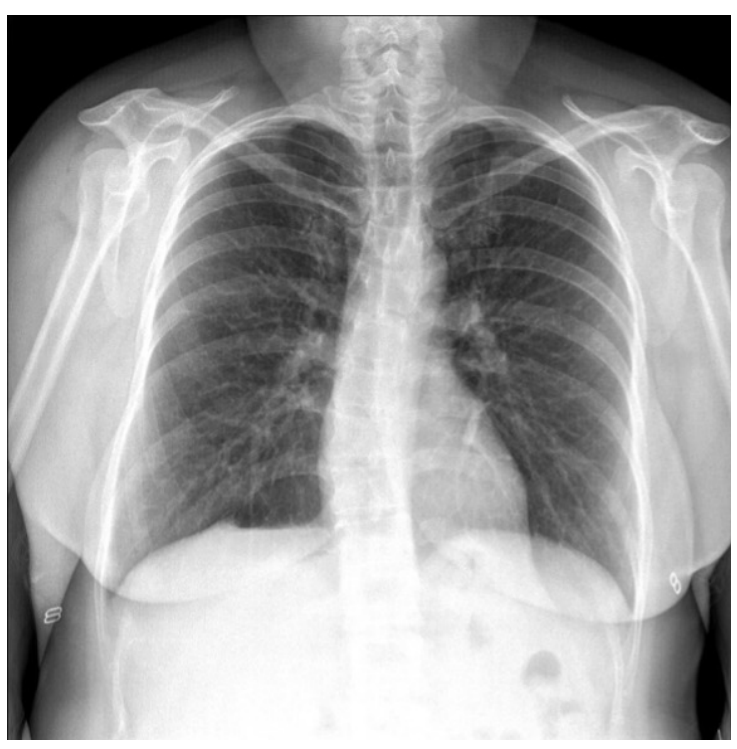

Resim 5. Normal akciğer grafisi

\section{Tartışma}

Brakial pleksus bloğu sonrası çeşitli komplikasyonlar görülebilir. Bunlar; diafragmatik paralizi birlikteliğinde frenik sinir bloğu (\%36-67), pnömotoraks $(\% 0,5-6,1)$, hematom $(\% 0,1-0,67)$ [3] ve intravasküler enjeksiyon sonrası gelişen lokal anestezi toksisitesidir $(\% 0,04-0,18)$ [4].

Frenik sinir anterior skalen kasının önünde yer alır ve onu brakial pleksustan ayıran tek yapı fasyasıdır. Pleksusun proksimal yani interskalen aralığa enjekte edilen lokal anestezikler bu aralıkta frenik sinirin de bulunması nedeniyle kolayca frenik siniri etkileyebilir [5]. Frenik sinir hasarından kaçınmak için sinir stimülatör cihazı kullanılarak abdominal hareketler takip edilebilir. Ayrıca ultrasonografi ile karın kaslarında paradoksal kasılmalar izlenebilir ve olası frenik sinir uyarımı gözlenebilir. Usg ve sinir stimülatör kullanımıyla beraber olası komplikasyonlar ciddi oranda azalma görülür [6]. Bizim olgumuzda usg ile eş zamanlı stimülatör cihazı kullanmamıza ve abdominal hareketleri takip etmemize rağmen bunun önüne geçilememiştir.

Frenik sinir hasarı sonrası diafragma paralizisine bağlı respiratuar semptomlar olabilir. Dispne, wheezing, azalmış solunum sesleri, ortopne, takipne, hipoventilasyon, intrabdominal basınç artışına bağı gastroözefageal reflü görülebilir [7]. Bizim olgumuzda işlem sonrası 20. dk'da ani gelişen dispne şikâyeti olmuş ve bu durum 4 saat sürmüştür. Solunum yetmezliği olan hastalarda brakial pleksus blokları kontrendikedir [8]. Bizim hastamızda blok için kontrendike bir durum söz konusu değildi.

Fenik sinir hasarı olan olgularda radyolojik görüntülemelerle tanı konur. Akciğer grafisi diafragma morfolojisi ve yüksekliğini değerlendirmede etkilidir. Akciğer grafisinin tek taraflı diyafragma paralizisi tanısında duyarlııı̆ı, özgüllüğü, pozitif ve negatif prediktif değeri sırasıyla $\% 90, \% 44, \% 33$ ve \%93'tür [9]. Tek taraflı frenik sinir hasarında aynı taraf diyafragmada hareketsizliğe bağlı yükseklik görülür. Floroskopi ile inspiryumda diyafragmanın parodoksik hareketinin gözlenmesi (Sniff test) genellikle tanı koydurur. Günümüzde floroskopi yerine daha çok Usg kullanılmaktadır ve parasagittal ve transvers pozisyonlarda diyafragma paradoks hareketinin görülmesi amaçlanmaktadır [9]. Bizim olgumuzda ani gelişen dispne ve inspiryumda çekilen akciğer grafisinde tek taraflı diyafragma yüksekliğinin olması tanıyı koydurdu.

Sonuç olarak, supraklaviküler brakial pleksus bloğunun usg ve sinir stimülatörü gibi ek yöntemler kullanılmasına rağmen ipsilateral hemidiyafragmatik paralizi insidansı halen yüksektir. Bu durum sağlıklı hastaların çoğunda asemptomatik seyretmektedir. Erken dönemde gelişen dispne şikâyeti, özellikle inspiryumda çekilen akciğer grafisi ile hızlı tanı koydurur. Bu hastaların yakın hemodinamik takibi için yoğun bakım önem arz etmektedir.

Çıkar ilişkisi: Yazarlar çıkar ilişkisi olmadığını beyan eder. 


\section{Kaynaklar}

1. Klein SM, Evans H, Nielsen KC, Marcy S Tucker MS, Warner DS, Steele SM. Peripheral nerve block techniques for ambulatory surgery. Anesth Analg 2005;101;1663-1676. https://doi.org/10.1213/01. ANE.0000184187.02887.24

2. Hadzic A. Hadzıc's textbook of Regıonal anesthesia and Acute pain management. 2. ed. McGraw-Hill Education, 2017:1315-1316.

3. Finucane BT. Complications of regional anesthesia. Second edition. Edmonton, Alberta, Canada 2007;121149. https://doi.org/10.1007/978-0-387-68904-3

4. Local anesthetic systemic toxicity. Available at: https://www.uptodate.com/contents/local-anestheticsystemic-toxicity. Accessed February 20, 2022

5. Partridge BL, Katz J, Benirschke K. Functional anatomy of the brachial plexus sheath: implications for anesthesia. Anesthesiology 1987;66:743-747. https:// doi.org/10.1097/00000542-198706000-00006

6. Hogan $Q H$. Phrenic nerve function after interscalene block revisited: now, the long view. Anesthesiology 2013;119;250-252. https://doi. org/10.1097/ALN.0b013e31829c2f3a

7. Reynaud V, Prigent H, Mulliez A, Durand MC, Lofaso F. Phrenic nerve conduction study to diagnose unilateral diaphragmatic paralysis. Muscle\&Nerve 2021;63:327335. https://doi.org/10.1002/mus.27144

8. Zisquit J, Nedeff N. Interscalene block. StatPearls Publishing, 2021.

9. Ricoy J, Rodríguez Núñez N, Álvarez Dobaño JM, Toubes ME, Riveiro V, Valdés L. Diaphragmatic dysfunction. Pulmonology 2019;25:223-235. https:// doi.org/10.1016/j.pulmoe.2018.10.008

Hasta onamı açıklaması: Hastadan yayın için aydınlatıımış yazılı ve sözlü onam alınmıştır. 